The following is a continuation of the ephemeris published by Herr M. Ebell :-

\begin{tabular}{|c|c|c|c|c|}
\hline 1904 & te & $\begin{array}{l}\text { oh. } M .1 \\
\text { h. } \\
\text { m. s. }\end{array}$ & entir & \\
\hline May 22 & $\ldots$ & 1437 10 & $\ldots$ & +5757 \\
\hline \# 26 & $\ldots$ & 142029 & $\ldots$ & $+5^{8} \mathrm{I}$ \\
\hline 30 & $\ldots$ & 14626 & $\ldots$ & +5744 \\
\hline
\end{tabular}

An error, due to the ambiguity of a necessarily brief telegram, was contained in a previous paragraph concerning this object. This comet is a new one discovered by Mr. Brooks, and not the Brooks's comet of 1896 returned.

Orbit of the Spectroscopic Binary $\iota$ Pegasi.-No. 53 of the Lick Observatory Bulletins is devoted to a detailed discussion of the definitive orbit of I Pegasi by Dr. Heber D. Curtis. The elements obtained have been derived from measurements of forty-three plates taken during the period October 7, 1897, and December I, 1903, inclusive.

Three sets of elements, each one giving a nearer approximation to the observed values than the one preceding it, were evolved, and the derivation of each set is given in full detail. The final set gives a velocity of $-4.12 \pm 0.11 \mathrm{~km}$., and a period of $10.21312 \pm 0.00006$ days. Owing to the small eccentricity of the orbit, viz. 0.0085 , the epoch of periastron is not very certain, but is given as 1899 June $14.966 \pm 0.352$ days.

\section{IRON AND STEEL INSTITUTE.}

THE annual meeting of the Iron and Steel Institute was held at the house of the Institution of Civil Engineers on May 5 and 6 under the presidency of Mr. Andrew Carnegie. The report of the council, read by the secretary, $\mathrm{Mr}$. Bennett $\mathrm{H}$. Brough, showed that the institute continues to make satisfactory progress. The president then presented the Bessemer gold medal to Mr. R. A. Hadfield (Sheffield). The announcement was made that awards of rool. from the Carnegie research fund had been made to John Dixon Brunton (Musselburgh), Dr. H. C. H. Carpenter (National Physical Laboratory), E. G. L. Roberts and E. A. Wraight conjointly (London), Frank Rogers (Cambridge), and Walter Rosenhain (Birmingham), and a renewed award of $50 l$. to $O$. Boudouard (Paris). The Andrew Carnegie gold medal for research was awarded to Pierre Breuil (Paris), and a special medal to Percy Longmuir (Sheffield).

The first paper read was by Mr. A. Dupré and Captain M. B. Lloyd, H.M. Inspector of Explosives, on explosions produced by ferrosilicon at Liverpool on January 12 and 21. The explosion was most probably caused by water having got into the interior of the drums containing the ferrosilicon; the gas evolved formed, with the air in the drums, an easily ignited explosive mixture, which was fired by the heat produced by the friction of the hard lumps against each other when the drums were moved about, or possibly by the spontaneous ignition of some phosphuretted hydrogen contained in a pocket in the material, and liberated suddenly by the breaking of a lump on the drum being moved. Although the accidents were not attended by very grave results, it is important that all those who have to handle ferrosilicon should be alive to the possible dangers attaching to it, and by keeping it in a dry and thoroughly well ventilated place prevent the accumulation of inflammable gas as far as possible.

Prof. H. Louis (Newcastle-on-Tyne) then read a paper on the manufacture of pig iron from briquettes at Herräng, Sweden. The mining and smelting of the ore present many novel features. Briefly the scheme of operations is as follows:-The ore as mined is conveyed from the various mines by aërial wire rope-ways to the crushing works, where it is broken and crushed wet; the pulp runs to the magnetic concentrators, which take out the magnetite; the latter is conveyed by a small aërial rope-way to the briquetting house, where it is stamped into briquettes, which pass next through the briquetting furnace, in which they are burnt; they are then hoisted up to the top of a pair of charcoal furnaces, where they are smelted for high-class pig iron; the waste gases from the blast furnace fire the briquetting furnaces, and supply gas-engines which furnish

NO. 1802, VOI. 70$]$ the blast and also drive the dynamos of a central electrical station, from which power is conveyed to the concentrating works, as well as to the various mines for hoisting, pumping; \&c. Several of the principles embodied appear destined to play an important part in the metallurgy of iron in the near future.

Mr. Cosmo Johns (Sheffield) read a paper on the production and thermal treatment of steel in large masses. He indicated some of the conditions which differentiate works' practice from laboratory research.

An interesting feature of the meeting was an exhibition of pyrometers. At the Barrow meeting of the Iron and Steel Institute; the suggestion was made that, in view of the growing importance of pyrometers to the steel industry, arrangements should be made to enable members to see the actual working of different pyrometers in order to enable them to form their own opinions of the relative merits of the appliances available for metallurgical purposes. The council readily adopted this suggestion, and appointed a committee, consisting of $\mathrm{Mr}$. R. A. Hadfield (vice-president), Mr. J. E. Stead (member of council), and Mr. B. H. Brough (secretary), to make the necessary arrangements for the exhibition. Invitations were sent to all the leading makers to exhibit pyrometers and to furnish brief descriptions of them. The descriptions occupied a pamphlet of sixty-two pages, and dealt with the following types:-(r) Baird and Tatlock pyrometer, (2) Bristol's recording air pyrometer, (3) Callendar and Griffith resistance pyrometer, (4) Le Chatelier pyrometer; (5) Mesuré and Nouel optical pyrometer, (6) Roberts-Austen recording pyrometer, (7) Rosenhain and Chalmers pyrometer, (8) Siemens electrical pyrometer, (9) Siemens water pyrometer, (ro) Uehling pneumatic pyrometer with Steinbart automatic recorder, (II) Wanner optical pyrometer, (I2) Wiborgh's thermophone, (13) Zaubitz pyrometer. In conclusion, a list of patents relating to pyrometry, compiled by $\mathrm{Mr}$. $\mathrm{H}$. G. Graves, and a full bibliography of the subject were given.

Mr. C. Lowthian Bell (Middlesbrough) read an important paper on the manufacture of coke in the Hüssener oven at the Clarence Iron Works, and its value in the blast furnace. The results show that with this oven a coke can be made giving as good results in the furnace as that made in the old beehive oven.

Dr. H. C. H. Carpenter and Mr. B. F. E. Keeling submitted $a$ paper on the range of solidification and the critical ranges of iron-carbon alloys. The research, which was carried out at the National Physical Laboratory, confirms, broadly speaking, the accuracy of Bakhuis-Roozeboom's diagram. Further, the results indicate that the diagram will be amplified in certain parts when the equilibrium between the various phases has been more fully studied, viz. on account of (x) the small thermal change at about $790^{\circ}$ for alloys with carbon content $0.8-4.5 ;(2)$ the slow thermal change at about $600^{\circ}$ found over the whole range of alloys; (3) the evolutions of heat at about $900^{\circ}$ found in alloys with carbon content of 3.87 and 4.50 .

Mr. H. C. Boynton (Harvard University) submitted a paper on troostite, in which he gave the results of experiments made with the object of furnishing facts in regard to the identity of this constituent of steel, which, although mentioned by prominent metallurgists, has not apparently been generally accepted or understood.

A paper on the synthesis of Bessemer steel was presented by Mr. F. J. R. Carulla (Derby), in which he gave particulars of the manufacture of steel rails in 1874 by the acid process of a quality so uniform as to leave nothing to be desired. He urges that modern requirements should be equally well fulfilled, and that endeavours should be made to introduce improvements in the Bessemer process so as to prevent its being altogether put aside in favour of the open-hearth process.

Mr. W. J. Foster (Darlaston) submitted a paper on the thermal efficiency of the blast furnace, in which he gave the results obtained with the furnace at Darlaston $72 \frac{1}{2}$ feet high, in which the materials smelted are chiefly silicates of iron.

Mr. W. Rosenhain (Birmingham) contributed a paper on the plastic yielding of iron and steel. He described some new observations explaining the curved slip-bands in iron and mild steel. This curvature is shown to be probably due to a multitude of minute steps, "and a reason is thus 
suggested why this stepping should be so marked a feature in iron, while it is so comparatively rare in certain other metals. This reason is that the ferrite crystals in ordinary iron and steel are formed by crystallisation from a solid solution, while the ordinary crystals of lead, for instance, are formed by crystallisation from a true liquid, The truly crystalline character of slip-bands is further demonstrated in a novel manner by the observation of slip-bands in iron following and revealing the gliding planes of twin crystals. Finally, the view has been advanced that the strength of inter-crystalline cohesion in pure metals and certain forms of alloys is due to the interlocking of the skeleton arms which the crystals develop during their first formation. According to this view, the inter-crystalline boundaries take the form of regions of mixed orientation, and certain consequences are to be deduced from this consideration. It is argued that, since a region of mixed orientation must offer greater resistance to slip than a region of uniform orientation, the intercrystalline boundaries form a network of cells upon which the true resistance of the metal depends. Plastic deformation sets in when these cell-walls begin to give way; in doing so they carry with them the less resisting masses of the crystalline grains. In this way the observed relation between slip-bands and inter-crystalline boundaries is explained. Observations of a frequent doubling of the intercrystalline boundaries between ferrite grains in pure iron and the "bordered boundaries" and "spines" in strained metal are adduced as further evidence in support of this view of the structure of inter-crystalline boundaries.

Mt. B. H. Thwaite (London) contributed a paper on the use of steel in American lofty-building construction. During the past five years some 200,000 tons of steel have been annually consumed in steel frame construction in the United States.

Mr. P. Breuil (Paris) submitted a report on the work carried out by him as a Carnegie research scholar. It dealt with the relations between the effects of stresses slowly applied and of stresses suddenly applied in the case of iron and steel. He showed that the tests made with nicked bars, a widely extending practice in France, were just like those made with plain bars, but much less clear and precise. The nicking of test bars simply introduces a further complication.

Mr. P. Longmuir (Sheffield) submitted a report on his research, as a Carnegie scholar, on the influence of varying casting temperature on the properties of steel and iron castings. With mild steels the influence of casting temperature does not appear to show on the tensile properties. Low casting temperatures, however, appear to induce a type of brittleness not evidenced in the tensile test, but shown in the working life of the metal. It is possible that many of the mysterious fractures of steel, which has previously passed a rigorous inspection, may be traced to the original ingot having been cast at too high or too low a temperature.

\section{THE SOUTH AFRICAN ASSOCIATION.}

THE second annual meeting of the South African Association for the Advancement of Science was held at Johannesburg during the week commencing April 4. At the opening meeting Lord Milner presided, and Sir Charles Metcalfe delivered his presidential address, which, in addition to a review of the scientific advances during the preceding year, contained a number of comments on some of the causes which have effected the great advances in scientific knowledge in recent years.

Portions of the address appeared in the Johannesburg Star, and we have selected from them a few extracts of scientific interest. The only address which has reached us is one given by Mr. E. B. Sargant on "The Education of Examiners," and an abridgement of this will probably appear in our next number. For the subjoined abstracts of other addresses and papers we are indebted to the Johannesburg Star.

\section{Presidential Address.}

Referring to diseases of stock, Sir Charles Metcalfe said :- In Rhodesia, Dr. Koch has been spending the whole year in laborious and patient investigation of the African coast fever among cattle, and he has now reported that he has found that it is caused by a blood parasite which can be readily identified by a demonstration of the specific organism, that it is different from Texas fever, or so-called red-water, that it is not transferable directly, that sick animals can be stabled with healthy ones without communicating the disease, and that the disease can only be spread by ticks. Further, that the blood of animals which have recovered and become immune is not free from parasites, and that the disease therefore can be produced in healthy animals by the transfer of parasites from salted animals by means of ticks, and though fencing, dipping and spraying are beneficial, yet as they have only a temporary value, Dr. Koch recommends that these precautions should be supplemented by inoculation with the blood of animals that have recovered whenever disease breaks out in the vicinity.

Turning to another subject, the president continued :the geodetic survey of Africa, the inception and continuation of which owe so much to our past president, Sir David Gill, is being proceeded with both in the Transvaal and in northern Rhodesia beyond the Zambezi. It is intended to extend it northwards more or less, probably along the route of the Cape to Cairo railway, that projected line which to many appears, perhaps, to belong to the things of dreamland. You, however, who know South Africa well will agree with me that in this country it has generally been found that the sanguine man has ever been the truest prophet. When this geodetic survey has been connected up with that of Europe, which has now been extended as far north as Spitsbergen, we shall have an arc from that point to Cape "lown-the longest arc that is possible to us on this glube. All civilised nations have found the advantage of having proper and accurate maps, and it is hoped that a useful work may now be undertaken in South Africa by a system of secondary triangulation. This work will necessarily take many years to complete; every year, however, the recorded results will be of value, as they will enable correct maps to be compiled showing the topography and main features of the country and the situation of the larger farms, of the most important and more populated districts in the first place, and then of the more remote parts of the country.

Introducing the subject of anthropological research, the president remarked that Prof. Haddon, when president of the Anthropological Institute, expressed himself strongly on the urgency of anthropological research. "In view," he said, " of the decrease of the native races by the advance of civilisation and the changes in the habits of the survivors, no time is to be lost in the acquisition of scientific knowledge by direct observations." There is wide scope and much opportunity in South Africa for such research, though Sir Charles Metcalfe said "the argument about their decrease and the use of the word 'survivors' read strangely to us, who see the native races not decreasing but happily increasing in numbers as well as in material prosperity."

Later in his address Sir Charles Metcalfe directed attention to the fact that for research into the causes and preventives of disease, both in human beings and in animals, there is a great field in South Africa. Continuing, he remarked, "The various Governments here have shown commendable vigour in dealing with those terrible scourges, rinderpest, plague, and red-water, and have acted in a spirit of the truest economy by securing the services of the most able men of science of the day in their investigation. When England was ravaged by rinderpest, no remedy was discovered; the animals affected were simply destroved at a cost of some nine millions of money. It was left for South Africa, at a later date, when knowledge was more advanced by the admirable work of the scientific investigators engaged on that task, to be the first to discover a preventive for that disease, a fact of which this country may well be proud. I have mentioned Dr. Koch's great work in the investigation of cattle fever in Rhodesia. $\mathrm{He}$ has also at the same time undertaken researches into some others of the diseases affecting animals in South Africa, amongst them that most familiar but terrible disease which we call horse-sickness, a disease by which the country loses not only many thousands of pounds annually by the deaths of valuable animals, but also the large amount

No. I 802 , VOL 707 